\title{
Design and Implementation of Internal Multi-band Folded Monopole Antenna for Mobile Station
}

\author{
Jun Ho Jeon, Woon Geun Yang, Yeon Chan Hong, Member, KIMICS
}

\begin{abstract}
In this paper, we designed and implemented an internal multi-band folded monopole antenna for mobile handset. The proposed antenna covers Global System for Mobile Communications (GSM900: 880 960 MHz), Digital Communications System (DCS: 1710 1880 MHz), USPersonal Communications Service (US-PCS: 1850 1990 MHz), Bluetooth(2400 2484 MHz), WiMAX(3400 3600 MHz), and Wireless Local Area Network (WLAN: 5150 5350 MHz, 5725 5875 MHz) band for Voltage Standing Wave Ratio $($ VSWR $) \leq 3$. The measured peak gains of the implemented antenna are $-1.78 \mathrm{dBi}$ at $920 \mathrm{MHz}, 2.72 \mathrm{dBi}$ at $1795 \mathrm{MHz}$, $2.25 \mathrm{dBi}$ at $1920 \mathrm{MHz}, 2.34 \mathrm{dBi}$ at $2442 \mathrm{MHz}, 2.11 \mathrm{dBi}$ at $3550 \mathrm{MHz}$, and $2.04 \mathrm{dBi}$ at $5250 \mathrm{MHz}$.
\end{abstract}

Index Terms - Folded Monopole Antenna (FMA), Intenna, Mobile Station, Multi-band.

\section{INTRODUCTION}

RECENTLY, it is strongly required for the mobile station to cover multi-band with a single internal type antenna. It has a close relation with an international roaming, multimedia service, wireless internet connection with a single terminal. Therefore, these demands for wireless terminal are an explosive issue. So, there are strong demands for small, lightweight, and compact mobile stations. These demands also require the development of a low-profile internal antenna with superior performances in terms of the impedance bandwidth and gain. However, the design of an internal antenna is technically challenging due to the limited antenna volume and influence of the mobile station housing and human body. The folded monopole type antenna is a good candidate for a mobile station because of its simple structure, omni-directional radiation pattern, low profile, and lightweight characteristics [1-5].

Many techniques of the folded monopole antenna have been developed to meet the needs for multi-band

\footnotetext{
Manuscript received January 7, 2011; revised February 1, 2011; accepted February 7, 2011.

Jun Ho Jeon is with the Department of Electronics Engineering, University of Incheon, Incheon, 406-772, Korea (Tel: +82-32-835-4767, Email: jeon@incheon.ac.kr

Woon Geun Yang is with the Department of Electronics Engineering, University of Incheon, Incheon, 406-772, Korea (Tel: +82-32-835-8447, Email:wgyang@incheon.ac.kr

Yeon Chan Hong(Corresponding Author) is with the Department of Electronics Engineering, University of Incheon, Incheon, 406-772, Korea (Tel: +82-32-835-8449, Email: ychong@incheon.ac.kr
}

operations for the third generation mobile system[6-9]. Folded Monopole Antenna (FMA) and Planar Inverted-F Antenna (PIFA) are widely used for mobile station applications. Especially monopole antennas have found widespread applications in wireless mobile communications systems[10].

In this paper, we propose a multi-band internal folded monopole antenna for mobile station. The proposed antenna covers Global System for Mobile Communications (GSM900: 880 960 MHz), Digital Communications System (DCS: 1710 1880 MHz), USPersonal Communications Service (US-PCS: 1850 1990 MHz), Bluetooth(2400 2484 MHz), WiMAX(3400 3600 $\mathrm{MHz}$ ), and Wireless Local Area Network (WLAN: 5150 $5350 \mathrm{MHz}, 5725 \sim 5875 \mathrm{MHz}$ ) frequency bands.

\section{PROPOSED ANTENNA}

The geometry of the proposed internal multi-band folded monopole antenna for operating at GSM900/DCS/ US-PCS/Bluetooth/WiMAX/WLAN frequency bands is shown in Fig. 1.

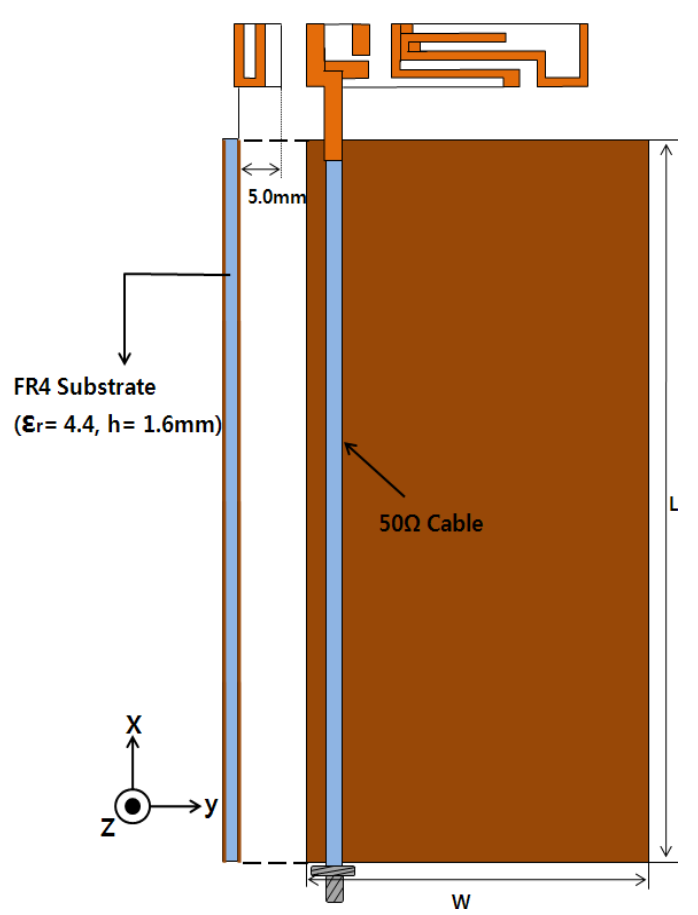

(a) 


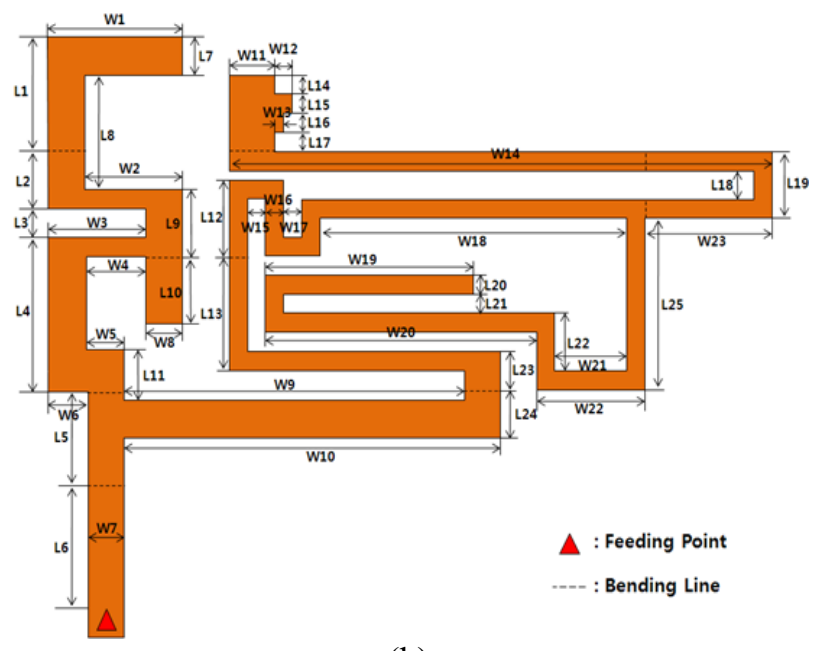

(b)

Fig. 1. Geometry of the proposed antenna. (a) Top and side view. (b) Detail dimensions of the proposed antenna.

The size of the proposed antenna is $33.0 \times 7.0 \times 5.0$ $\mathrm{mm}^{3}$. And the ground plane is $40(\mathrm{~W}) \times 80(\mathrm{~L}) \mathrm{mm}^{2}$ and a FR4 substrate with the thickness of $1.6 \mathrm{~mm}$ and relative permittivity of 4.4 is used.

Table 1 shows the design parameters of the proposed antenna.

TABLE I

DESIGN PARAMETERS OF THE PROPOSED ANTENNA

\begin{tabular}{|c|c|c|c|}
\hline Parameter & $\begin{array}{l}\text { Length } \\
\text { (mm) }\end{array}$ & Parameter & $\begin{array}{c}\text { Length } \\
\text { (mm) }\end{array}$ \\
\hline w & 40.00 & L & 80.00 \\
\hline W1 & 7.40 & L1 & 6.00 \\
\hline W2 & 5.40 & L2 & 3.00 \\
\hline W3 & 5.40 & L3 & 1.50 \\
\hline W4 & 3.30 & L4 & 7.00 \\
\hline W5 & 2.10 & L5 & 5.00 \\
\hline w6 & 2.20 & L6 & 8.00 \\
\hline W7 & 2.00 & L7 & 2.00 \\
\hline W8 & 2.00 & L8 & 6.00 \\
\hline w9 & 18.80 & L9 & 3.50 \\
\hline W10 & 20.80 & L10 & 5.54 \\
\hline W11 & 2.50 & L11 & 2.65 \\
\hline W12 & 1.00 & L12 & 4.00 \\
\hline W13 & 0.50 & L13 & 6.00 \\
\hline W14 & 27.50 & L14 & 1.00 \\
\hline W15 & 1.00 & L15 & 1.00 \\
\hline W16 & 1.00 & L16 & 1.00 \\
\hline W17 & 1.00 & L17 & 1.00 \\
\hline W18 & 17.00 & L18 & 6.00 \\
\hline W19 & 11.50 & L19 & 3.47 \\
\hline W2O & 15.00 & L20 & 1.00 \\
\hline W21 & 4.00 & L21 & 1.00 \\
\hline W22 & 6.00 & L22 & 3.00 \\
\hline \multirow[t]{3}{*}{ W23 } & 7.00 & L23 & 2.00 \\
\hline & & L24 & 2.54 \\
\hline & & L25 & 7.00 \\
\hline
\end{tabular}

\section{SIMULATION AND MEASUREMENT}

The commercial program High Frequency Structure Simulator (HFSS) from Ansoft based on the Finite Element Method (FEM) is used to obtain suitable values of parameters and analyze the behavior of the proposed antenna. And the measurement of electrical characteristics such as radiation patterns and return loss of the implemented antenna were conducted in an anechoic chamber equipped with a HP8510C network analyzer and far field measurement system.

Fig. 2 shows the excited surface current distributions obtained from the HFSS simulation on the radiation element of the proposed antenna at $920 \mathrm{MHz}, 1795 \mathrm{MHz}$, $1920 \mathrm{MHz}, 2442 \mathrm{MHz}, 3500 \mathrm{MHz}$, and $5250 \mathrm{MHz}$.

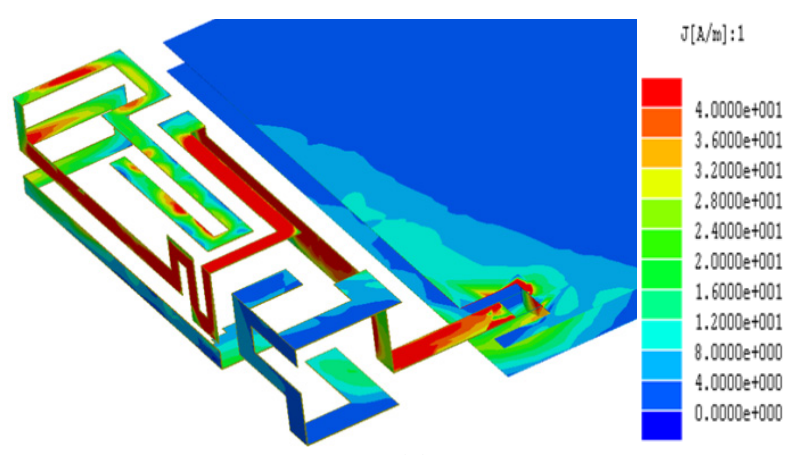

(a)

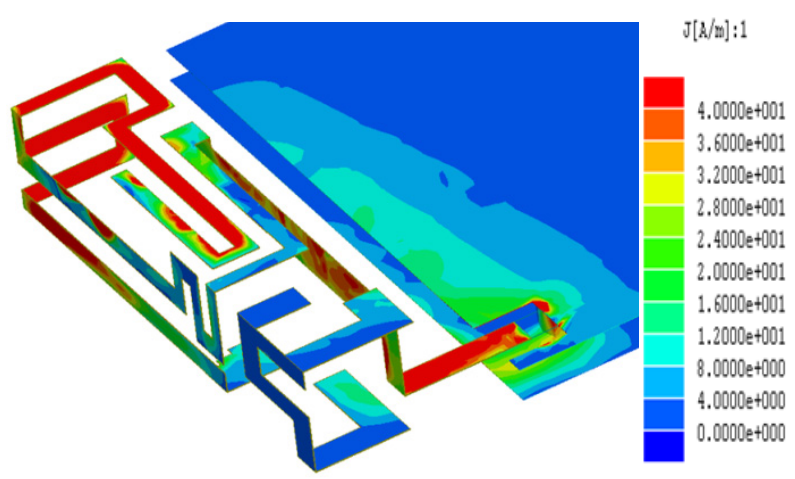

(b)

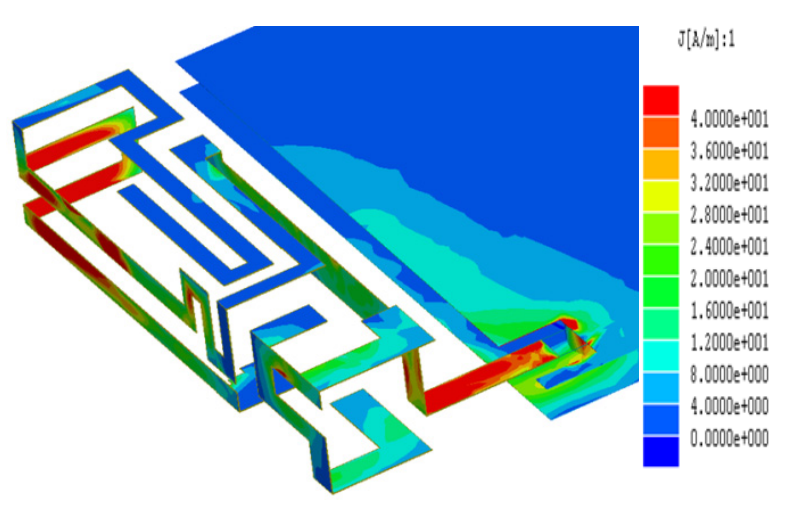

(c) 


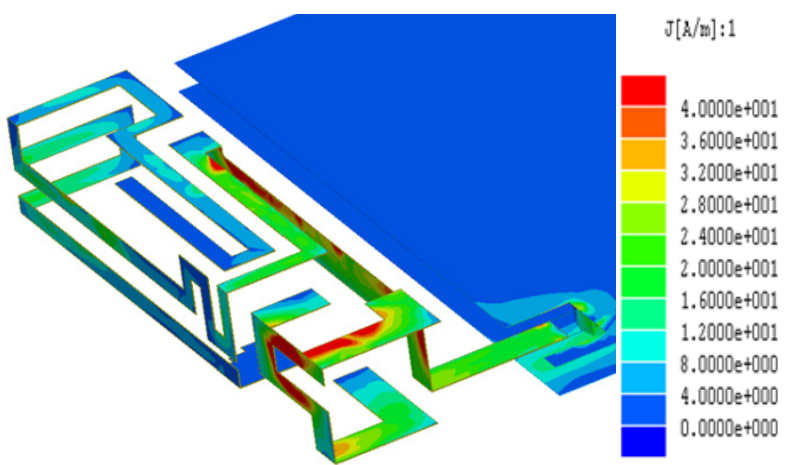

(d)

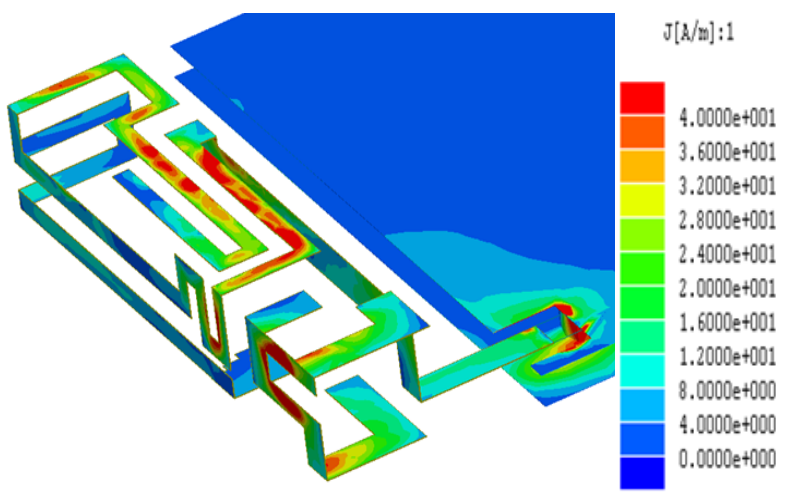

(e)

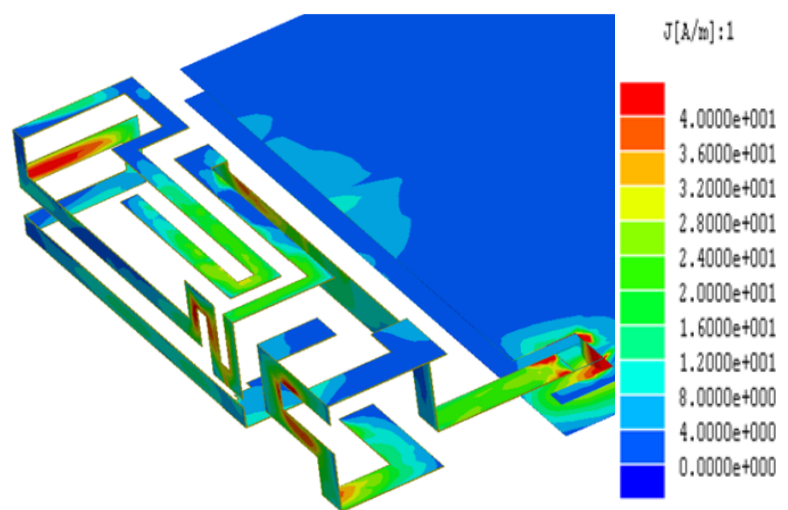

(f)

Fig. 2. Current distribution of the proposed antenna. (a) at $920 \mathrm{MHz}$. (b) at $1795 \mathrm{MHz}$. (c) at $1920 \mathrm{MHz}$. (d) at 2442MHz. (e) at $3500 \mathrm{MHz}$. (f) at $5250 \mathrm{MHz}$.

From the Fig. 2, we can see the corresponding major radiation element for each frequency bands. There are three branches. For low frequency band, long branch plays a major roll. And short branch operates for high frequency band.

Fig. 3 shows measurement and simulation results on the return loss of the proposed antenna. Reasonable agreement between measurement and simulation is observed, and demonstrates that the proposed antenna covers GSM900/DCS/US-PCS/Bluetooth/WiMAX/WLAN frequency bands for Voltage Standing Wave Ratio $($ VSWR $) \leq 3$.

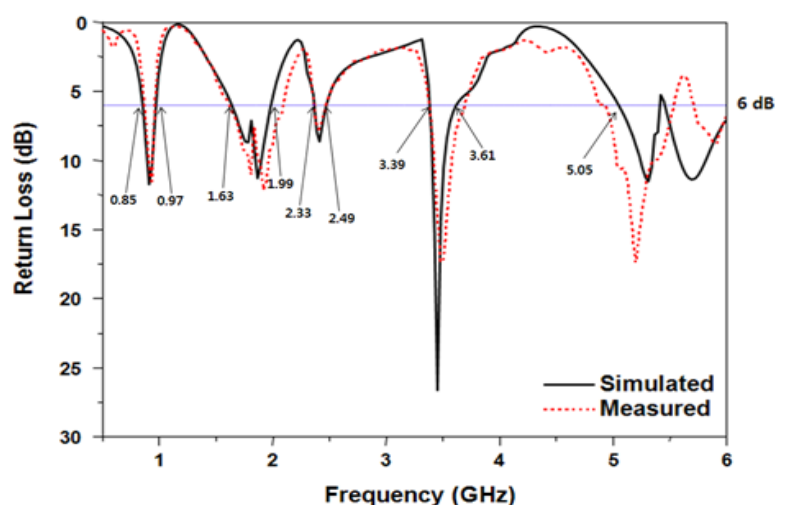

Fig. 3. Simulation and measurement result on the return loss of the proposed antenna.

Fig. 4 shows the measured co-polarization and cross-polarization radiation patterns in the $x-y$ plane (elevation plane), $y-z$ plane(azimuth plane) and $z-x$ plane(elevation plane) for the proposed antenna at 920 MHz, $1795 \mathrm{MHz}, 1920 \mathrm{MHz}, 2442 \mathrm{MHz}, 3550 \mathrm{MHz}$, and $5250 \mathrm{MHz}$. At all the frequencies, radiation patterns are nearly omni-directional in the $y$-z plane.

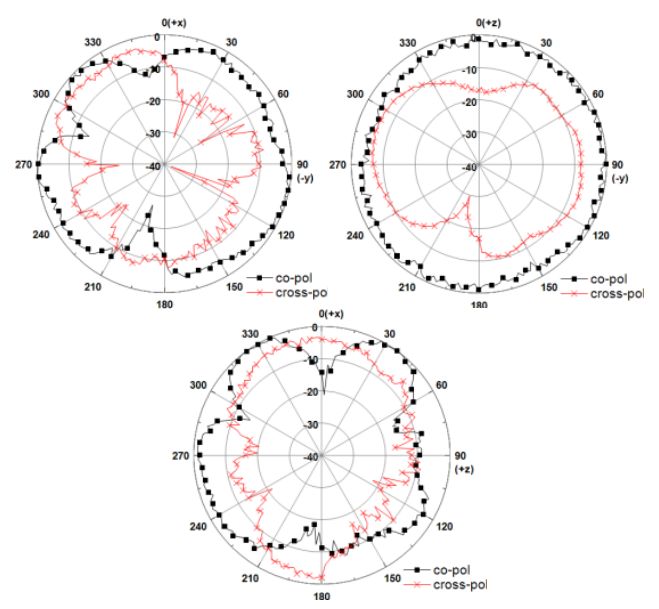

(a)

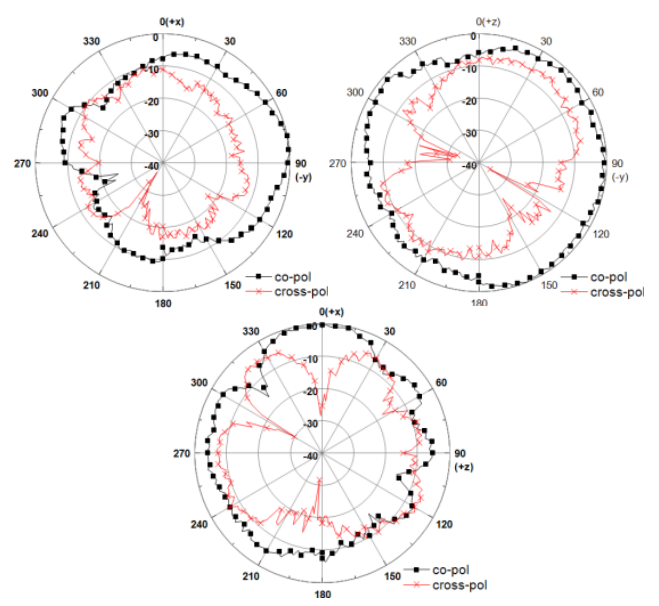

(b) 


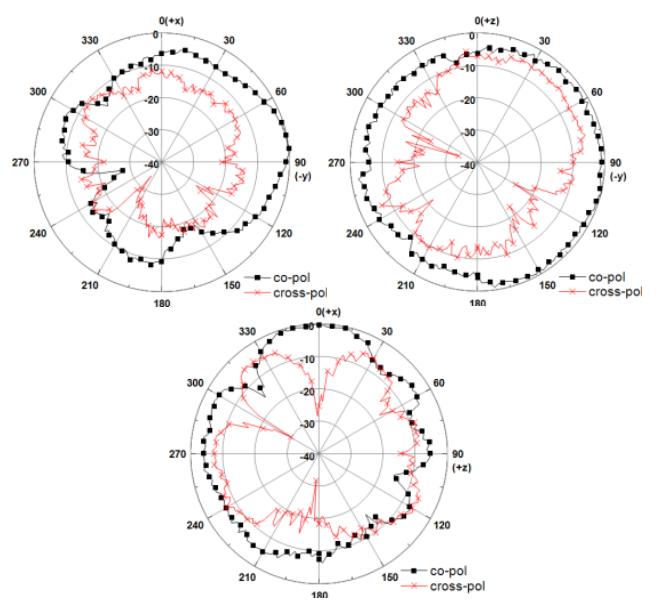

(c)

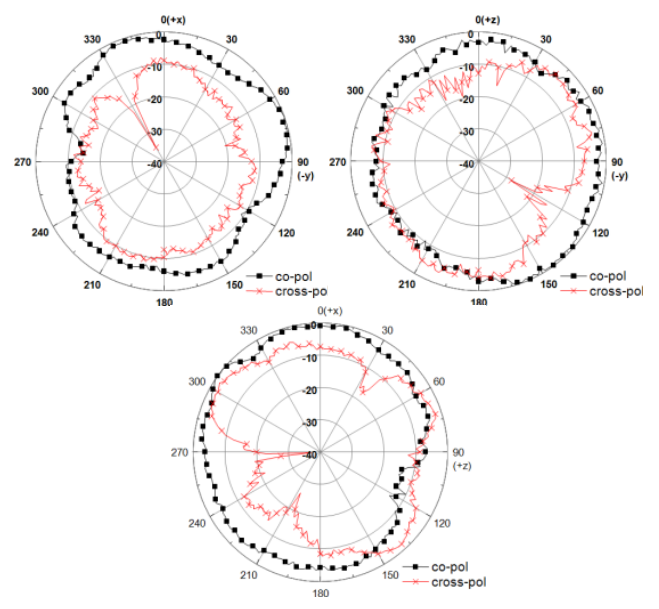

(d)

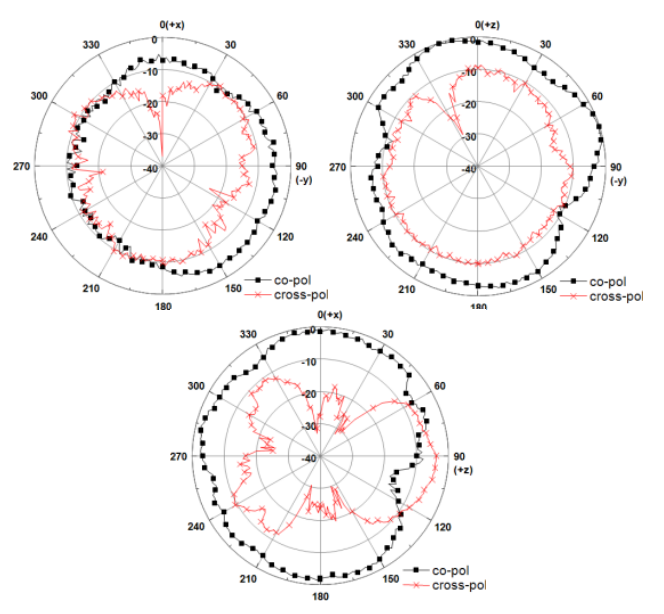

(e)

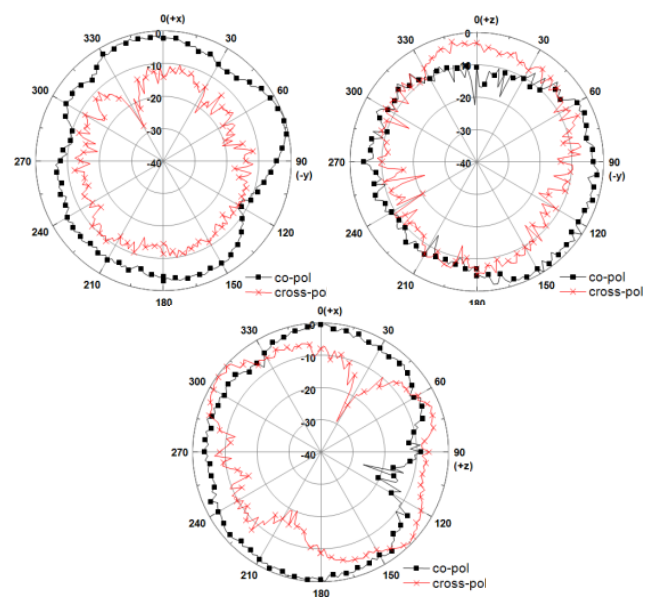

(f)

Fig. 4. Measured radiation patterns of the implemented antenna. (a) at $920 \mathrm{MHz}$. (b) at $1795 \mathrm{MHz}$. (c) at 1920MHz. (d) at 2442MHz. (e) at 3500MHz. (f) at $5250 \mathrm{MHz}$,

Table 2 shows results of the antenna maximum peak gain and average gain measurement. From Table 2, the implemented antenna shows suitable gain performances.

TABLE II

\section{RESULTS OF THE ANTENNA GAIN MEASUREMENT}

\begin{tabular}{|c|c|c|}
\hline \multirow{2}{*}{$\begin{array}{c}\text { Frequency } \\
\text { Band }\end{array}$} & \multicolumn{2}{|c|}{ Gain (dBi) } \\
\cline { 2 - 3 } $\begin{array}{c}\text { GSM900 } \\
(920 \mathrm{MHz})\end{array}$ & Peak & Ave. \\
\hline $\begin{array}{c}\text { DCS } \\
(1795 \mathrm{MHz})\end{array}$ & -1.78 & -4.21 \\
\hline $\begin{array}{c}\text { US-PCS } \\
(1920 \mathrm{MHz})\end{array}$ & 2.72 & -2.54 \\
\hline $\begin{array}{c}\text { Bluetooth } \\
(2442 \mathrm{MHz})\end{array}$ & 2.25 & -1.68 \\
\hline $\begin{array}{c}\text { WiMAX } \\
(3500 \mathrm{MHz})\end{array}$ & 2.34 & -0.85 \\
\hline $\begin{array}{c}\text { WLAN } \\
(5250 \mathrm{MHz})\end{array}$ & 2.11 & -1.51 \\
\hline
\end{tabular}

\section{CONCLUSION}

We proposed a multiband internal folded monopole antenna for mobile station. We designed and implemented the multi-band internal folded monopole antenna for GSM900, DCS, US-PCS, Bluetooth, WiMAX, and WLAN frequency bands.

The implemented antenna shows a return loss less than $6 \mathrm{~dB}(\mathrm{VSWR} \leq 3)$ at GSM900/DCS/US-PCS/Bluetooth /WiMAX/WLAN frequency bands. The measured peak gains are $-1.78 \mathrm{dBi}$ at $920 \mathrm{MHz}, 2.72 \mathrm{dBi}$ at $1795 \mathrm{MHz}$, $2.25 \mathrm{dBi}$ at $1920 \mathrm{MHz}, 2.34 \mathrm{dBi}$ at $2442 \mathrm{MHz}, 2.11 \mathrm{dBi}$ at $3550 \mathrm{MHz}$, and $2.04 \mathrm{dBi}$ at $5250 \mathrm{MHz}$. The proposed 
multiband internal folded monopole antenna has good radiation patterns characteristics.

We expect that the implemented antenna can be used for GSM900/DCS/US-PCS/Bluetooth/WiMAX/WLAN application.

\section{ACKNOWLEDGMENT}

This work was supported by the University of Incheon Research Grant in 2010.

\section{REFERENCES}

[1] R. A. Bhatti, Y. T. Im, and S. O. Park, "Compact PIFA for Mobile Terminals Supporting Multiple Cellular and Non-Cellular Standards," IEEE Trans. Antenna and Propag., vol. 57, no. 9, pp. 2534-2540, 2009.

[2] J. H. Jeon, J. B. Yu, C. K. An, W. C. Kim, and W. G. Yang, "Design and Implementation of Multi-Band Internal PIFA with Rectangular Slit for Mobile Station," ICEIC 2010 Cebu, pp. 87-90, 2010.

[3] J. B. Yu and W. G. Yang, "Design and Implementation of MultiBand Folded Monopole Antenna for Mobile Handset Applications," IJMICS, vol. 8, no. 6, pp. 630-634, 2010.

[4] C. L. Liu, Y. F. Lin, C. M. Liang, S. C. Pan, and H. M. Chen, "Miniature Internal Penta-Band Monopole Antenna for Mobile Phone," IEEE Trans. Antenna and Propag., vol. 58, pp. 1008-1011, 2010.

[5] K. S. Kim, S. B. Park, S. M. Kim, and W. G. Yang, "Penta-Band Internal Antenna for Mobile Handset Applications," Microwave and Optical Technology Letter, vol. 50, no. 12, pp. 3045-3048, 2008.

[6] S. M. Kim, K. S. Yoon, S. B. Park, W. G. Yang, N. K. Kim, and J. H. Lee, "Multi-Band Internal Monopole Antenna for Mobile station," Microwave and Optical Technology Letter, vol. 50, no. 1, pp. $241-244,2008$.

[7] S. Hong, W. Kim, S. Kahng, and J. Choi, "Design of an Internal Multiresonant Monopole Antenna for GSM900/ DSC1800/ USPCS/ S- DMB operation," IEEE Trans. Antenna and Propag., vol. 56, no, 5, pp. 1437-1443, 2008.

[8] H. W. Hsieh, Y. C. Lee, K. K. Tiong, and J. S. Sun, "Design of a Multiband Antenna for Mobile Handset Operations," IEEE Antennas and Wireless Propagation Letters., vol. 8, pp. 200-203, Apr. 2009.

[9] J. H. Maeng, J. B. Yu, C. K. An, J. H. Jeon, and W. G. Yang, "Combined PIFA and monopole with rectangular slot and parasitic element for mobile handset," International Symposium on Antennas and Propag., Bangkok, Thailand, pp. 81-84, 2009.

[10] S. Lin, G. Wang, K. Pan, X. Ge, and Y. Yang, "A novel dualfrequency monopole for WCDMA and $2.5 \mathrm{GHz}$ extension band," Microwave and Millimeter Wave Technology, 2010 International Conference, pp. 362-365, 2010.

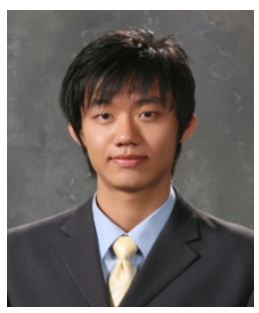

Jun Ho Jeon received his B.S. degree in electronics engineering from the University of Incheon, Incheon, South Korea, in 2009. Since March 2009, he has been the M.S. student in electronics engineering, University of Incheon, South Korea. His research interests include mobile antennas and DMB rod antenna with trap.

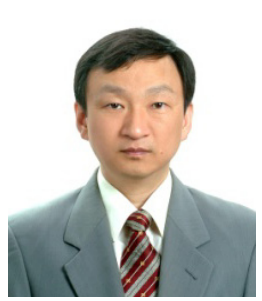

Woon Geun Yang received his B.S., M.S. and $\mathrm{Ph} . \mathrm{D}$. degrees in electronics engineering from Seoul National University, Seoul, South Korea, in 1983, 1985 and 1994, respectively. From 1988, he has been the faculty of Dept. of electronics engineering, University of Incheon, Incheon, South Korea. From March, 1997 to Dec., 2001, and from Feb., 2004 to Jan., 2005, he had been a consulting professor for LG Electronics Inc. including former LG Information \& Communications Co., Ltd. From May, 2001 to Feb., 2002, he was an invited researcher in ETRI (Electronics and Telecommunications Research Institute). His name has been listed in the "Who's Who in the World" since 2003. His research interests include mobile communication, antenna, RFID, SAR.

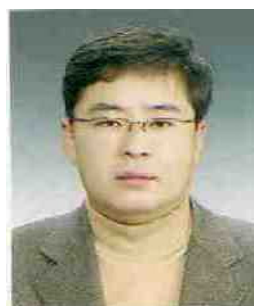

Yeon Chan Hong received his B.S., M.S. and $\mathrm{Ph} . \mathrm{D}$. degrees in electronics engineering from Seoul National University, Seoul, South Korea, in 1983, 1985 and 1989, respectively. From 1992, he has been the faculty of Dept. of electronics engineering, University of Incheon, Incheon, South Korea. His research interests include Control Engineering, RFID, GMDH, Neural Network. 